\title{
Sex-specific Analysis of Data in High-impact Orthopaedic Journals: How Are We Doing?
}

\author{
Carolyn M. Hettrich MD, MPH, Sommer Hammoud MD, Lauren E. LaMont MD $\mathbb{}$, \\ Elizabeth A. Arendt MD, Jo A. Hannafin MD, PhD
}

Received: 9 February 2014 / Accepted: 7 July 2015 / Published online: 22 July 2015

(C) The Association of Bone and Joint Surgeons(B 2015

\begin{abstract}
Background In 2001, the Institute of Medicine released a report stating that sex must be considered in all aspects and at all levels of biomedical research. Knowledge of differences between males and females in responses to treatment serves to improve our ability to care for our patients.

Questions/purposes The purpose of our study was to determine (1) if there is an increase in the proportion of sex-specific reporting from 2000 to 2005 and to 2010; and (2) whether there is a proportional difference in such reporting based on journal type: subspecialty versus general orthopaedics. We hypothesize that assessment of the role of sex in outcomes has improved during the past 15 years and that the proportion of studies with of sex-specific
\end{abstract}

Each author certifies that he or she, or a member of his or her immediate family, has no funding or commercial associations (eg, consultancies, stock ownership, equity interest, patent/licensing arrangements, etc) that might pose a conflict of interest in connection with the submitted article.

All ICMJE Conflict of Interest Forms for authors and Clinical Orthopaedics and Related Research ${ }^{\mathbb{R}}$ editors and board members are on file with the publication and can be viewed on request.

C. M. Hettrich

Department of Orthopaedics and Rehabilitation, University

of Iowa Sports Medicine Center, Iowa City, IA, USA

S. Hammoud

Rothman Institute, Philadelphia, PA, USA

L. E. LaMont ( $₫)$, J. A. Hannafin

Hospital for Special Surgery, 310 E 71st Street, New York, NY 10021, USA

e-mail: lelamont@gmail.com

E. A. Arendt

Department of Orthopaedic Surgery, University of Minnesota, Minneapolis, MN, USA analyses has increased with awareness of the role of sex in clinical outcomes and disease states. We additionally hypothesized that the reporting of sex would be similar between subspecialty and general orthopaedic journals.

Methods Five high-impact orthopaedic journals, consisting of two general and three subspecialty journals, were chosen for review. Issues from even-numbered months during three calendar years $(2000,2005,2010)$ were critically assessed for the presence of sex-specific analyses and reporting by two separate reviewers. Retrospective and prospective clinical studies, with a minimum of 20 patients, were included for analysis. Cadaveric, biomechanical, and in vitro studies were excluded. Review articles and clinical studies with less than 20 patients were excluded. A total of 821 studies that met inclusion criteria were analyzed: 206 in 2000, 277 in 2005, and 338 in 2010.

Results Overall, the proportion of sex-specific analyses increased during the three times studied (19\%, 40/206, [95\% CI, 0.14-0.25] of the studies in 2000; 27\%, 77/277, [95\% CI, 0.23-0.33] in 2005; and 30\%, 102/338, [95\% CI, $0.25-0.35]$ in 2010). The increase in the proportion of sexspecific analysis was significant between 2000 and 2005 $(\mathrm{p}=0.033)$, but was not significant between 2005 and 2010 $(\mathrm{p}=0.518)$. During each of the three specific years studied, general and subspecialty journals increased in the proportions that reported sex-based analyses, but specialty journals had significantly higher reporting rates only in 2000 (2000: 11.9\%, 13/109, [95\% CI, 0.06-0.18] and $27.8 \%, 27 / 97$, [95\% CI, 0.19-0.37], $\mathrm{p}=0.004 ; 2005$ : $22.9 \%, 33 / 144$, [95\% CI, 0.16-0.30], and 33.1\%, 44/133, [95\% CI, 0.25-0.41], $\mathrm{p}=0.059 ; 2010: 28.2 \%, 51 / 181$, [95\% CI, 0.22-0.35] and 32.5\%, 51/157, [95\% CI, $0.25-0.40], \mathrm{p}=0.390$ ).

Conclusions Our findings indicate that inclusion of sexspecific analysis and reporting in the orthopaedic literature 
improved during our study period, but are present in less than $1 / 3$ of the studies. Although subgroup analysis and reporting are required by NIH guidelines, it is important that such analyses be published in non-NIH-funded studies to generate hypotheses regarding sex differences for subsequent research. These data also are important as they can be used in systematic reviews where large independent studies may not be available in the literature.

Clinical Relevance Where evaluating conditions that affect males and females, studies should be designed with sufficient sample size to allow for subgroup analysis by sex to be performed, and they should include sex-specific differences among the a priori research questions.

\section{Introduction}

Significant differences in the prevalence of medical and orthopaedic conditions and treatment outcomes between males and females have been identified and reported (Table 1) [2, 3, 6-8, 10, 13, 16, 19, 20, 22, 24]. Recognizing the importance of research on sexual dimorphism, the NIH instituted a policy in 1986 urging the inclusion of women in clinical trials. This policy became law in 1994 with the NIH Revitalization Act, which requires that NIH-supported clinical research include women as subjects [21]. Soon after the NIH Revitalization Act took effect, the Agency for
Health Research and Quality and the CDC developed similar guidelines [1, 5]. In 2001, the Institute of Medicine released a report stating that sex must be considered in all aspects and at all levels of biomedical research [14].

With the continued emphasis on including women in clinical trials, and reporting outcomes by sex [18], we were interested in evaluating whether clinical research published in the orthopaedic literature included sex-specific data stratification. Specifically, we aimed to determine (1) if there is an increase in the proportion of sex-specific reporting from 2000 to 2005 and to 2010; and (2) whether there is a proportional difference in such reporting based on journal type: subspecialty versus general orthopaedics.

\section{Materials and Methods}

Five of the highest-impact orthopaedic journals were chosen for review. Two general orthopaedic journals were chosen (Journal of Bone and Joint Surgery American Volume, and Clinical Orthopaedics and Related Research $^{\circledR}$ ) along with three subspecialty journals (Journal of Shoulder and Elbow Surgery, Spine, and American Journal of Sports Medicine). Issues published during evennumbered months of 2000, 2005, and 2010 were critically assessed for the presence of sex-specific analyses; a total of 126 journal issues were reviewed. Two independent

Table 1. Known musculoskeletal differences between males and females

\begin{tabular}{lc}
\hline Musculoskeletal parameter & Sex differences \\
\hline ACL tear & Female athletes are up to six times more likely to rupture their ACL compared with their male \\
counterparts participating in the same sport [7]. \\
Men have substantially larger knee cartilage volume than women, even after adjusting for age, height, \\
weight, and bone volume [6]. \\
Men have more muscle mass than women, and hence have greater losses in total muscle mass; \\
however, women experience earlier strength losses and have greater declines in muscle quality. As \\
Muscle \\
a result, women are more likely to have health problems from this owing to longer lifespan [8]. \\
Musculoskeletal pain is more prevalent in older women than older men, and men and women differ in \\
the factors associated with musculoskeletal pain [19]. \\
Worldwide estimates are that 9.6\% of men and 18.0\% of women 60 years old or older have \\
symptomatic osteoarthritis [2, 20]. \\
Before 50 years of age, the prevalence of osteoarthritis in most joints is greater in men than women, \\
but after this age, more women than men are affected by osteoarthritis of the hand, foot, and knee \\
[3, 13, 24]. \\
Osteoporosis, which is characterized by loss of bone mass leading to increased risk of fracture, affects \\
eight million women and two million men [22]. \\
One in two women and one in four men older than 55 years will have an osteoporosis-related fracture \\
[10, 22]. \\
The rate of hip fracture is two to three times higher in women than men; however, after a hip fracture, \\
men are nearly twice as likely as women to die [10, 22]. \\
Women had a 23\% greater mortality rate than men after one or more vertebral fractures [16]. \\
Osteoporosis
\end{tabular}


reviewers (SH and LL) performed the assessments. Articles were screened first via the abstract for the inclusion of males and females in the study. If the article qualified, the Materials and Methods and Results were reviewed to determine if sex was included as a variable in the statistical analysis or simply as a demographic. To be marked as having sex-specific analysis an article had to include sex in a multifactorial statistical model. There was third-party adjudication for any discrepancies in interpretation of the analysis of sex by a senior author $(\mathrm{CH})$.

Prospective and retrospective clinical studies with a minimum of 20 patients were included for analysis. Studies were excluded if they were nonhuman, cadaveric, biomechanical, in vitro, or review articles. Clinical studies with less than 20 patients were excluded from the analysis owing to lack of sufficient sample size to perform basic sex-specific analyses. Studies on teams or groups that did not include women also were excluded. In total, 206 articles met our inclusion criteria for 2000, 277 for 2005, and 338 for 2010.

To assess the proportion of sex-specific analyses reported in the three years, we generated a $2 \times 3$ table and performed chi-square analysis. We then performed subgroup analysis for each year, comparing general versus specialty on the proportion of sex-specific reporting. All analyses were performed by a statistician (YG).

\section{Results}

Overall, the proportion of sex-specific analyses increased during the three times studied (19\%, 40/206, [95\% CI, $0.14-0.25$ ] of the studies in 2000; 27\%, 77/277, [95\% CI, $0.23-0.33$ ] in 2005; and 30\%, 102/338, [95\% CI, 0.25-0.35] in 2010) (Fig. 1). The increase in the proportion

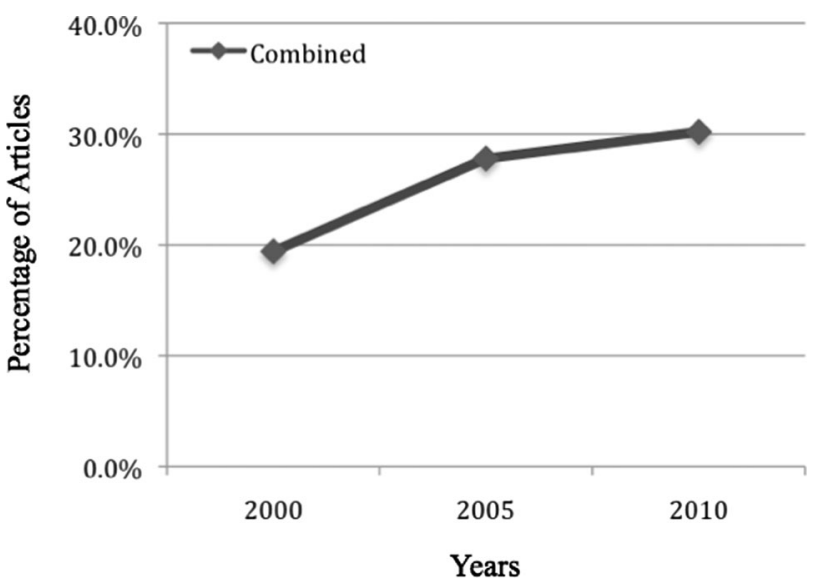

Fig. 1 The percentages of articles that included sex-specific analyses in all journals combined for 2000, 2005, and 2010 are shown. of sex-specific analysis was significant between 2000 and $2005(\mathrm{p}=0.033)$, but was not significant between 2005 and $2010(\mathrm{p}=0.518)$.

During the three years studied, general and subspecialty journals increased in the proportions that reported sexbased analyses (Table 2). Specialty journals had significantly higher reporting rates only in 2000 (2000: 11.9\%, 13/109, [95\% CI, 0.06-0.18] and 27.8\%, 27/97, [95\% CI, $0.19,0.37], \mathrm{p}=0.004 ; 2005: 22.9 \%, 33 / 144,[95 \% \mathrm{CI}$, $0.16-0.30$ ], and $33.1 \%, 44 / 133$, [95\% CI, 0.25-0.41], $\mathrm{p}=$ $0.059 ; 2010: 28.2 \%, 51 / 181,[95 \% \mathrm{CI}, 0.22-0.35]$ and $32.5 \%, 51 / 157$, [95\% CI, 0.25-0.40], $\mathrm{p}=0.390$ ) (Fig. 2).

\section{Discussion}

In 2001, the National Academy of Sciences Institute of Medicine published its report entitled Exploring the Biological Contributions to Human Health: Does Sex Matter? [25]. Their findings supported the importance of sex as an important variable in design and analysis of all health research [25]. Furthermore, the report emphasized that "understanding the bases of these sex-based differences [is] important to developing new approaches to prevention, diagnosis, and treatment [25]. Similarly the NIH recognizes an ethical principal of justice and importance of balancing research burdens and benefits across the population. This focus is evident in the NIH Revitalization Act of 1993, PL 103-43, which resulted in guidelines for the inclusion of women and minorities in clinical research [21]. Geller et al. [11, 12] looked at such inclusion and found that in federally funded randomized controlled trials on average, $37 \%$ of the study participants were women, showing their underrepresentation [11, 12]. Seventy-five percent of these studies did not report any outcomes by sex [12]. Rates of inclusion and data stratification did not improve during the 5-year period reviewed [11, 12]. Moreover, they found no differences in the rates of sexspecific data stratification in reporting or analysis when comparing 25 nonfederally funded studies with the federally funded studies, which were bound by the guidelines of the NIH and other federal funding agencies [12].

Recently, Clinical Orthopaedics and Related Research $^{\circledR}$ published an editorial calling for increased inclusion, reporting, and analysis of sex and gender in all submitted studies [18]. The editorial emphasized the important differences between sex and gender and the implications in orthopaedics [18]. Because of this emphasis on sex-specific analysis and reporting, and because little is known regarding the current baseline of reporting in orthopaedics, we aimed to determine whether sex-specific reporting increased with time and if there were differences between general and subspecialty journals. 
Table 2. Percentage of studies with sex-specific analyses by journal

\begin{tabular}{|c|c|c|c|}
\hline Journal/year & Total & Women & Percent \\
\hline \multicolumn{4}{|l|}{2000} \\
\hline Journal of Bone \& Joint Surgery, American Volume & 42 & 2 & $4.76 \%$ \\
\hline American Journal of Sports Medicine & 40 & 13 & $32.50 \%$ \\
\hline Clinical Orthopaedics and Related Research ${ }^{\mathbb{R}}$ & 67 & 11 & $16.42 \%$ \\
\hline Spine & 45 & 11 & $24.44 \%$ \\
\hline Journal of Shoulder and Elbow Surgery & 12 & 3 & $25.00 \%$ \\
\hline Total & 206 & 40 & $19.42 \%$ \\
\hline \multicolumn{4}{|l|}{2005} \\
\hline Journal of Bone \& Joint Surgery, American Volume & 77 & 22 & $28.57 \%$ \\
\hline American Journal of Sports Medicine & 41 & 13 & $31.71 \%$ \\
\hline Clinical Orthopaedics and Related Research ${ }^{\circledR}$ & 67 & 11 & $16.42 \%$ \\
\hline Spine & 55 & 16 & $29.09 \%$ \\
\hline Journal of Shoulder and Elbow Surgery & 37 & 15 & $40.54 \%$ \\
\hline Total & 277 & 77 & $27.80 \%$ \\
\hline \multicolumn{4}{|l|}{2010} \\
\hline Journal of Bone \& Joint Surgery, American Volume & 64 & 25 & $39.06 \%$ \\
\hline American Journal of Sports Medicine & 64 & 22 & $34.38 \%$ \\
\hline Clinical Orthopaedics and Related Research ${ }^{\circledR}$ & 117 & 26 & $22.22 \%$ \\
\hline Spine & 52 & 21 & $40.38 \%$ \\
\hline Journal of Shoulder and Elbow Surgery & 41 & 8 & $19.51 \%$ \\
\hline Total & 338 & 102 & $30.18 \%$ \\
\hline
\end{tabular}

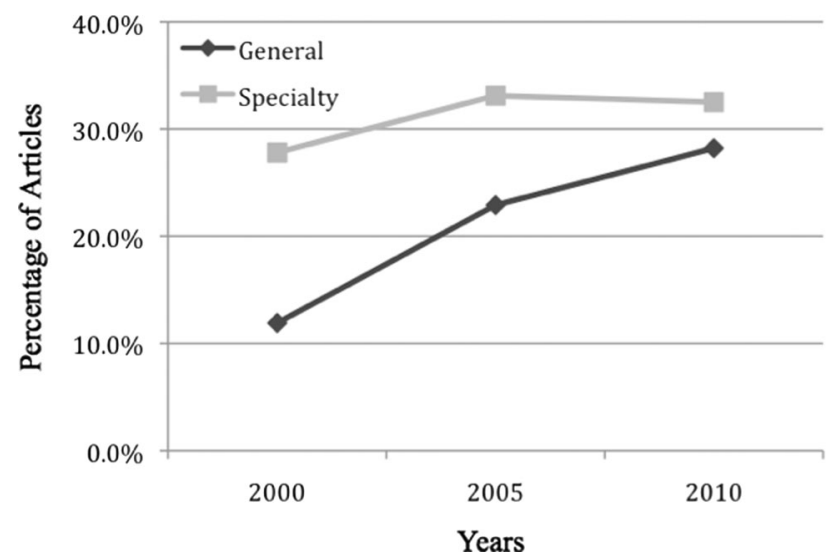

Fig. 2 The percentages of articles that included sex-specific analyses in general versus specialty journals in 2000, 2005, and 2010 are shown.

The most important limitation of our study is lack of knowledge of the percentage of studies that should include a sex-specific analysis, as this is not practical for all studies. For certain studies, and certain diseases, it may not be practical to obtain sufficient patient numbers to perform a multivariable analysis. Increasing numbers of patients to levels to adequately perform these analyses potentially would increase costs and make analyses more complex, requiring a statistician. Data were taken from 2000, 2005, and 2010, and although it would be more illustrative to include every year, we thought this was a representative sample, with years spaced enough to show changes with time.

We found an increase in sex-specific analyses with time, most significantly between 2000 and 2005 in general and subspecialty journals. In $2010,70 \%$ of orthopaedic studies did not include a sex-specific analysis, similar to the $75 \%$ cited by Geller [12]. Similar concerns regarding inclusion and appropriate sex-specific result reporting are found across multiple medical specialties and are particularly prevalent in the cardiovascular literature $[4,15,17,25]$. Circulation, a journal of the American Heart Association, has responded favorably by instructing authors to provide sex-specific data when appropriate in describing outcomes of epidemiologic analysis or clinical trials. Moreover, the journal requires authors to specifically state that no sex-based differences were present when none are found. Perhaps orthopaedic journals should institute similar policies requiring authors to clearly label single-sex studies and include a statement justifying the inclusion of only one sex in their research design or justifying why there was no sex-specific data stratification in their analysis. Researchers continue to acknowledge these differences and focus groups to better analyze them, such as the Gendered Innovations project that develops methods of sex analysis [23]. The American Academy of Orthopaedic Surgeons has emphasized the 
importance of sex-specific information for medical devices through the Health of Women program [9].

Inclusion of sex-specific analyses increased in the orthopaedic literature during the years we studied, however, $70 \%$ of the clinical studies included did not include a sex-specific analysis. Although it is not practical to include a sex-specific analysis in all studies, it is imperative for educators and researchers to promote and support data stratification by sex in clinical and basic science research. Understanding how males and females may present differently with similar diagnoses and/or respond differently to various treatments can translate into orthopaedic clinical practice and ultimately improve patient care and outcomes.

Acknowledgments We thank Yubo Gao $\mathrm{PhD}$, Department of Orthopaedics and Rehabilitation, University of Iowa, (Iowa City, IA, USA), for assistance with statistical analysis.

\section{References}

1. Agency for Health Research and Quality (AHRQ). Policy on the Inclusion of Priority Populations in Research. Available at: http:// grants.nih.gov/grants/guide/notice-files/NOT-HS-03-010.html. Accessed July 4, 2015.

2. Arthritis Foundation. Osteoarthritis. Available at: http://www. arthritis.org/arthritis-facts/disease-center/osteoarthritis.php. Accessed April 17, 2015.

3. Ateshian GA, Rosenwasser MP, Mow VC. Curvature characteristics and congruence of the thumb carpometacarpal joint: differences between female and male joints. J Biomech. 1992;25:591-607.

4. Blauwet LA, Hayes SN, McManus D, Redberg RF, Walsh MN. Low rate of sex-specific result reporting in cardiovascular trials. Mayo Clin Proc. 2007;82:166-170.

5. Centers for Disease Control (CDC). Inclusion of Women and Racial and Ethnic Minorities in Research. Available at: http:// www.cdc.gov/maso/Policy/Policy_women.pdf. Accessed July 5, 2015.

6. Cicuttini F, Forbes A, Morris K, Darling S, Bailey M, Stuckey S. Gender differences in knee cartilage volume as measured by magnetic resonance imaging. Osteoarthritis Cartilage. 1999;7: 265-271.

7. Cowley HR, Ford KR, Myer GD, Kernozek TW, Hewett TE. Differences in neuromuscular strategies between landing and cutting tasks in female basketball and soccer athletes. $J$ Athl Train. 2006;41:67-73.

8. Doherty TJ. The influence of aging and sex on skeletal muscle mass and strength. Curr Opin Clin Nutr Metab Care. 2001;4:503-508.

9. Fassbender E. FDA puts spotlight on health of women: workshop kicks off new CDRH program. AAOS Now. August 2013. Available at: http://www.aaos.org/news/aaosnow/aug13/advocacy1.asp. Accessed September 23, 2013.
10. Follin SL, Hansen LB. Current approaches to the prevention and treatment of postmenopausal osteoporosis. Am J Health Syst Pharm. 2003;60:883-901; quiz 903-904.

11. Geller SE, Adams MG, Carnes M. Adherence to federal guidelines for reporting of sex and race/ethnicity in clinical trials. $J$ Womens Health (Larchmt). 2006;15:1123-1131.

12. Geller SE, Koch A, Pellettieri B, Carnes M. Inclusion, analysis, and reporting of sex and race/ethnicity in clinical trials: have we made progress? J Womens Health (Larchmt). 2011;20:315-320.

13. Hart DJ, Doyle DV, Spector TD. Incidence and risk factors for radiographic knee osteoarthritis in middle-aged women: the Chingford Study. Arthritis Rheum. 1999;42:17-24.

14. Institute of Medicine. Exploring the biological contributions to human health: does sex matter? Available at: www.iom.edu/ Reports/2001/Exploring-the-Biological-Contributions-to-HumanHealth-Does-Sex-Matter.aspx. Accessed July 5, 2015.

15. Jagsi R, Motomura AR, Amarnath S, Jankovic A, Sheets N, Ubel PA. Under-representation of women in high-impact published clinical cancer research. Cancer. 2009;115:3293-3301.

16. Kado DM, Browner WS, Palermo L, Nevitt MC, Genant HK, Cummings SR. Vertebral fractures and mortality in older women: a prospective study. Study of Osteoporotic Fractures Research Group. Arch Intern Med. 1999;159:1215-1220.

17. Kim AM, Tingen CM, Woodruff TK. Sex bias in trials and treatment must end. Nature. 2010;465:688-689.

18. Leopold SS, Beadling L, Dobbs MB, Gebhardt MC, Lotke PA, Manner PA, Rimnac CM, Wongworawat MD. Fairness to all: gender and sex in scientific reporting. Clin Orthop Relat Res. 2014;472:391-392.

19. Leveille SG, Zhang Y, McMullen W, Kelly-Hayes M, Felson DT. Sex differences in musculoskeletal pain in older adults. Pain. 2005; 116:332-338.

20. Murray CJ, Lopez AD, eds. The global burden of disease: a comprehensive assessment of mortality and disability from diseases, injuries, and risk factors in 1990 and projected to 2020. Cambridge, MA: Harvard School of Public Health on behalf of the World Health Organization and The World Bank; 1996. Available at: http://apps.who.int/iris/bitstream/10665/41864/1/ 0965546608_eng.pdf. Accessed July 6, 2015.

21. National Institutes of Health. NIH guidelines on the inclusion of women and minorities as subjects in clinical research. Available at: http://grants.nih.gov/grants/guide/notice-files/not94-100.html. Accessed April 17, 2015.

22. National Osteoporosis Foundation. Fast facts on osteoporosis. Available at: http://nof.org/articles/235. Accessed July 5, 2015.

23. Schiebinger L, Klinge I, Sánchez de Madariaga I, Schraudner M, Stefanick M, eds. Gendered Innovations in Science, Health \& Medicine, Engineering and Environment. Available at: http:// genderedinnovations.stanford.edu/what-is-gendered-innovations. html. Accessed April 17, 2015.

24. Valkenburg HA. Clinical versus radiological osteoarthritis in the general population. In: Peyron JG, ed. Epidemiology of Osteoarthritis. Paris, France: Ciba-Geigy; 1980;53-58.

25. Wizemann TM, Pardue ML, eds. Exploring the Biological Contributions to Human Health: Does Sex Matter? Washington, DC: National Academy Press; 2001. 